\title{
EFFECTIVENESS OF MUSIC PLAYBACK ON INTRAVENOUS CANNULATION PAIN AMONG CHILDREN
}

\author{
Ms. Reshma P. S*, Mrs. Anju A. R**, Mrs. Evangeline J**, Mrs. Sabitha S** \\ *Student, Josco College of Nursing, Edappon, Mavelikkara, Kerala, India. \\ **Professor, Josco College of Nursing, Edappon, Mavelikkara, Kerala, India. \\ DOI: http://doi.org/10.47211/tg.2020.v07i03.013
}

\begin{abstract}
A quasi experimental study was conducted to assess the effectiveness of music playback on intravenous cannulation pain among children in a selected hospital. Objectives: to assess the mean posttest pain score among children in the experimental and control group, to find out the effectiveness of music playback on intravenous cannulation pain among children and to find out the association between posttest pain score and selected socio demo graphic variables of children in control group. Quasi experimental posttest only controls group design and convenience sampling technique was used to select 60 children in a selected hospital at Alappuzha district. Conceptual framework: Ernestine Wiedenbach's Helping Art of Clinical Nursing Theory (1969). Posttest was conducted in the control and the experimental group by using FLACC Behavioral Pain Scale and Socio demographic proforma. Music playback was played to the experimental group for 10 minutes during intravenous cannulation. The data were tabulated and analysed using descriptive and inferential statistics. The mean posttest pain score of children in the experimental group was 4.1 with SD 1.33 which was significantly lower than the mean posttest pain score of children in the control group which was 7.8 with SD 1.27 with a mean difference of 3.6. The calculated ' $t$ ' value 10.910 was greater than the table value 2.00 , is significant at $p<0.05$ level with degree of freedom 58. Hence, we can conclude that the music playback was effective in reducing the pain level of children during intravenous cannulation. The analysis showed that the calculated chi square value for family monthly income, number of previous hospitalisations, previous exposure of cannulation were greater than that of the table value at $p<0.05$ level of significance. Hence null hypothesis (HO2) can be rejected and research hypothesis $(\mathrm{H} 2)$ can be accepted. So, it can be concluded that there was significant association between posttest pain score and socio demographic variables.
\end{abstract}

Keywords: Effectiveness; Music playback; Pain; Intravenous cannulation; Children.

\section{ABOUT AUTHORS:}

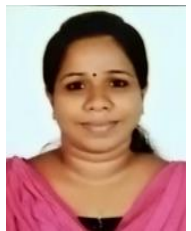

Ms. Reshma P. S is student of Josco College of Nursing, Edappon, Mavelikara, Kerala, India. She has attended various national, international conferences and work shop.

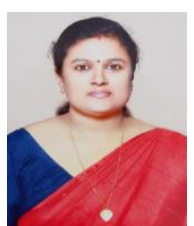

Mrs. Anju A. R is Professor of Josco College of Nursing, Edappon, Mavelikara, Alapuzha, Kerala, India. She has presented various conferences and work shop.

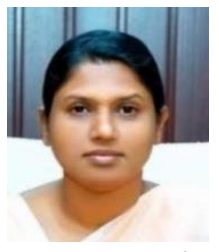

Mrs. Evangilene. J is Professor and Principal of Josco College of Nursing, Edappon, Mavelikara, Alapuzha dist, Kerala, India. She has published various research papers and attended national and international conferences and workshops.

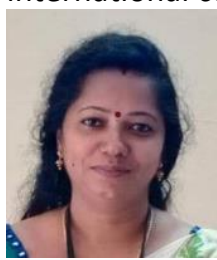

Mrs. Sabitha $S$ is Professor of Josco College of Nursing, Edappon, Mavelikara, Alapuzha, Kerala, India. She has presented various conferences and work shop. 


\section{INTRODUCTION}

Children are vital to the Nation's present and its future. ${ }^{1}$ Failure to alleviate pain results in an uncooperative child, unsuccessful procedures, prolonged procedure time and dissatisfaction with care for all involved. ${ }^{2}$ Venepuncture has been reported to be the most common painful event for hospitalized child. About $28 \%-83 \%$ of paediatric patient are diagnosed with acute behavioural distress during routine venepuncture test. ${ }^{3}$ Venepuncture is one of the most commonly experienced procedures by children and $50 \%$ of children experience significant levels of pain and distress during venepuncture. Among these, the distraction technique, non-pharmacological method can become an effective way of handling the children's behavioural response since it is easy, economical and needs limited training. ${ }^{4}$ The data summary for 1992 to 2004 from the American Pain Society reveals $70 \%$ of hospitalized children reported pain, almost $30 \%$ reported moderate pain and $15 \%$ reported extremely severe pain. ${ }^{5}$

\section{Background of the problem}

A quasi experimental study was conducted at Kochi (2014) to assess the effectiveness of distraction technique on pain relief during intravenous cannulation among 60 school children in the age group of 7-12 years in selected paediatric ward at Amrita Institutes of Medical Science by using Oucher Pain Intensity Scale - Asian version revealed that, $50 \%$ of them experience significant level of distress during intravenous cannulation. Among the children in the experimental group, who were distracted with cartoon, only $1(3.3 \%)$ had experienced severe hurt and 19(63.3\%) had experienced moderate hurt, 10(33.3\%) had experienced mild hurt. Whereas among the children, in the control group, who were not distracted with cartoon, a majority of $25(87.3 \%)$ had experienced severe hurt and $5(16.7 \%)$ had experienced moderate hurt and none of them had mild level pain. ${ }^{6}$

\section{Need and significance of the problem}

The pain response is individual and is learned through social learning and experience. Early pain experience may play a particularly important role in shaping an individual's pain response. Inadequate relief of pain and distress during childhood painful medical procedures may have long-term negative effects on future pain tolerance and pain responses. ${ }^{7}$ Many hospitalized children have undergone painful procedures. Besides the negative experiences of pain itself, growing evidences support the occurrence of long-term negative effects from inadequately treated pediatric pain, especially in preschoolers. ${ }^{8}$

\section{Statement of the problem}

A study to assess the effectiveness of music playback on intravenous cannulation pain among children in a selected hospital at Alappuzha district.

\section{OBJECTIVES}

1. To assess the mean posttest pain score among children in experimental and control group.

2. To find out the effectiveness of music playback on pain during intravenous cannulation among children.

3. To find out the association between posttest pain score and selected socio demographic variables of children in control group.

\section{HYPOTHESES}

$\mathrm{H} 1-$ There is a significant difference in mean posttest pain score among children in experimental group and control group.

$\mathrm{H} 2$-There is a significant association between posttest pain score and selected socio demographic variables of children in control group.

\section{ASSUMPTIONS}

$>$ Intravenous cannulation causes pain in children and can be relieved through proper diversion techniques.

$>$ Music play back may help to reduce pain.

\section{VARIABLES}

\section{Demographic variables}

Variables were age, education of the children, gender, birth weight, birth order, religion, place of residence, type of family, number of siblings, education of father, education of mother, occupation of father, occupation of mother, monthly income of the family, care giver present during intravenous cannulation, number of previous hospitalization, previous exposure to intravenous cannulation, type of admission, present weight of the child, reason for intravenous cannulation, reason for hospitalisation, site of cannulation, size of cannula \& number of cannulation attempts.

\section{Dependent variable}

Intravenous cannulation pain

Independent variable

Music playback 


\section{METHODOLOGY}

Research approach

Quantitative research approach.

Research Design

Quasi experimental posttest only controls group design.

Population

Target population

Children (3-7 years)

Accessible population

Children with 3-7 years who were undergoing intravenous cannulation in pediatric ward of Government hospital, Kayamkulam at Alappuzha district.

Sample size: 60(experimental-30, control-30)

Sampling technique: Non-probability convenience sampling technique.

Setting: Pediatric ward in Government hospital, Kayamkulam.

\section{TOOLS AND TECHNIQUES}

Tool 1: Socio demographic proforma.

Technique: Structured Interview Schedule.

Tool 2: Standardized FLACC behavioral pain scale.

Technique: Direct non-participatory structured observation method.

Development of Tool

- Review of literature.

- Personal consultation with guide, research coordinator, subject experts, experts from pediatric medicine and child health nursing and statisticians.

- Discussion with colleagues.

Reliability of Tool

The reliability was then estimated by inter rater reliability method. The ' $r$ ' value was calculated and has been found to be 1 . This indicates that the tool was highly significant.

Conceptual framework: Wiedenbach's helping art of Clinical Nursing Theory (1969).

Inclusion criteria

Children those who were:-

- in the age group of 3-7 years undergoing intravenous cannulation

- $\quad$ getting consent from parents

- $\quad$ both male and female children

- available during the time of data collection

\section{Exclusion criteria}

Children those who were:-

- having any neurological deficit

- under pain medication

- having emergency admission

\section{Data collection process}

Step 1: For conducting main study, formal written permission from the Medical Superintendent and District Medical Officer of the hospital. The data collection was done from 01/01/19 to 31/01/19.

Step 2: Informed consent, socio demographic proforma from the parents of control group and Posttest pain level of 3-4 samples per day for 30 samples from day $1^{\text {st }}$ to day $15^{\text {th }}$ using FLACC behavioral pain scale in control group by the researcher while the intravenous cannulation procedure was done by staff nurse. No intervention given for control group.

Step 3: Informed consent, socio demographic proforma from the parents of experimental group and intervention (music playback) was given by the researcher for 3-4 samples per day for 30 samples from day $16^{\text {th }}$ to day $31^{\text {st }}$. Pain was measured by the assistant using FLACC behavioral pain scale while the intravenous cannulation procedure was done by staff nurse.

Data Analysis

Descriptive: Frequency, percentage distribution, Mean percentage and standard deviation.

Inferential: Unpaired ' $t$ ', Chi-square test.

RESULTS

Section I: Distribution of subjects according to Socio demographic variables.

- $56.6 \%$ of the subjects were in the age group of 3-5 years in the experimental group. Whereas, $53.3 \%$ of the subjects were in the age group of 5-7 years in the control group. 
- $36.6 \%$ of the subjects were studying in kinder garden in the experimental group. While, $36.6 \%$ of the subjects were studying in pre-primary in the control group.

- $60 \%$ of the subjects were females in the experimental group. Whereas, $53.3 \%$ of the subjects were males in the control group.

- $63.3 \%$ of the subjects weighed between $2.5-3.5 \mathrm{~kg}$ in the experimental group. Whereas, $70 \%$ of the subjects weighed between $2.5-3.5 \mathrm{~kg}$ in the control group.

- $60 \%$ of the subjects were of the first birth order in the experimental group. Whereas, $60 \%$ of the subjects were of the first birth order in the control group.

- $53.3 \%$ of the subjects had no siblings in the experimental group. Whereas, $46.6 \%$ of the subjects had one sibling in the control group.

- $63.3 \%$ of the subjects were Hindus in the experimental group. While, $60 \%$ of the subjects were Hindus in the control group.

- $66.6 \%$ of the subjects were residing in municipalities in the experimental group. Whereas, $70 \%$ of the subjects were residing in municipalities in the control group.

- $66.6 \%$ of the subjects belonged to joint families in the experimental group. Whereas, $63.3 \%$ of the subjects belonged to joint families in the control group.

- $33.3 \%$ of the subjects' fathers had up to high school education in the experimental group. While, $63.3 \%$ of the subjects' fathers had higher secondary education in the control group.

- $33.3 \%$ of the subjects' mothers had higher secondary education in the experimental group. Whereas, 33.3\% of subjects' mothers had higher secondary education in the control group.

- $43.3 \%$ of the subjects' fathers were private employees in the experimental group. While, $43.3 \%$ of the subjects' fathers were private employees in the control group.

- $76.6 \%$ of the subjects' mothers were homemakers in the experimental group. But, $63.2 \%$ of the subjects' mothers were homemakers in the control group.

- $50 \%$ of subjects had monthly family income of Rs. 10,001 - Rs.20,000 in the experimental group. While, $63.3 \%$ of the subjects' family had monthly income of Rs. 5001-10,000 in the control group.

- $70 \%$ of the subjects were accompanied by mothers in the experimental group. While, $76.6 \%$ of the subjects were accompanied by mothers in the control group.

- $36.6 \%$ of the subjects had no previous hospitalisation in the experimental group. Whereas, $46.6 \%$ of the subjects had 1-2 times previous hospitalisation in the control group.

- $36.6 \%$ of the subjects had no previous exposure of cannulation in the experimental group. But, $46.6 \%$ of the subjects had 1-2 times previous exposure to cannulation in the control group.

-100\% were in the direct admission in the experimental and the control group.

- $53.3 \%$ of the subjects weighed between $15-20 \mathrm{~kg}$ in the experimental group. While, $56.6 \%$ of the subjects weighed between $10-15 \mathrm{~kg}$ in the control group.

- $70 \%$ of the subjects for medication administration in the experimental group. Whereas, $70 \%$ of the subjects for medication administration in the control group.

- $36.6 \%$ of the subjects had other complaints in the experimental group. Whereas, $40 \%$ of the subjects had lower respiratory tract infection in the control group.

- $93.3 \%$ of the subjects' site of cannulation was dorsum in the experimental group. While, $86.6 \%$ of the subjects' site of cannulation were dorsum in the control group.

- $96.6 \%$ of the subjects had $24 \mathrm{G}$ cannula in the experimental group and the control group.

- $53.3 \%$ of the subjects had one attempts in the experimental group. Whereas, $46.6 \%$ of the subjects had one attempt in the control group. 


\section{ARTICLES}

Section II: Assessment of mean posttest pain score among children in the control group.

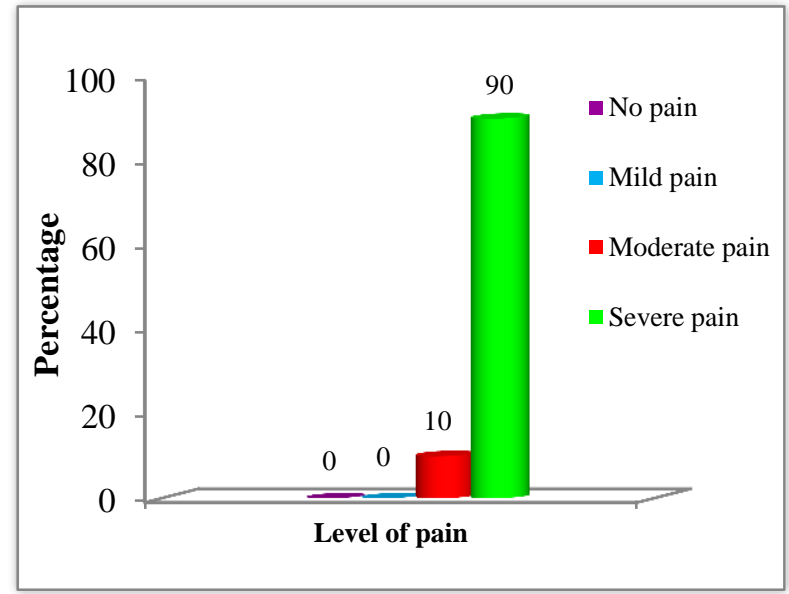

Section III: Assessment of mean posttest pain score among children in the experimental group.

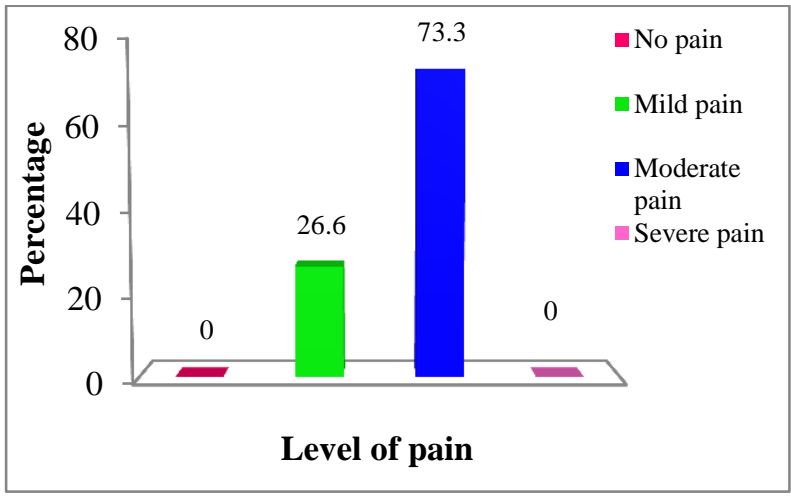

Section IV: Comparison of mean posttest pain score among children in the experimental and the control group.

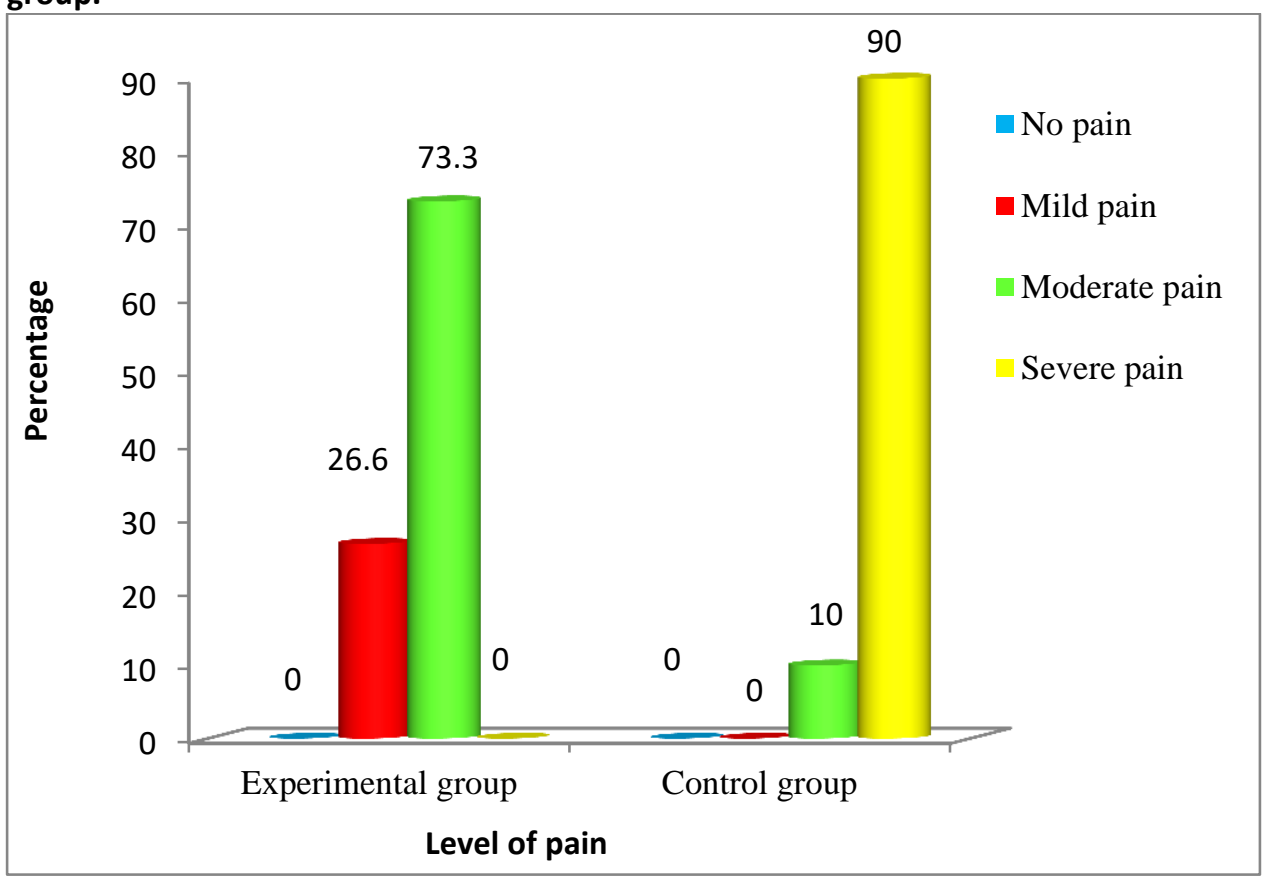


Section V: Effectiveness of music playback on intravenous cannulation pain among children.

Table 1: Mean, SD, Mean difference and calculated' $t$ ' value of posttest pain score among children in experimental and control group.

\begin{tabular}{llcl} 
& & $(\mathrm{n}=60)$ \\
\hline Group & Mean SD & $\begin{array}{c}\text { Mean df } \\
\text { Difference }\end{array}$ \\
\hline
\end{tabular}

Experimental $4.1 \quad 1.33$

\begin{tabular}{|c|c|c|}
\hline & & -3.6 \\
\hline
\end{tabular}

Section VI: Association between posttest pain score and selected socio-demographic variables of preschoolers in control group.

The calculated chi square value for family monthly, number of previous hospitalisation and previous exposure of cannulation were greater than that of the table. Hence null hypothesis ( $\mathrm{HO2}$ ) can be rejected and research hypothesis $(\mathrm{H} 2)$ can be accepted. So it can be concluded that there was significant association between posttest pain score and socio demographic variables like monthly income of family, number of previous hospitalisation and previous exposure of cannulation in the control group.

\section{RECOMMENDATION}

A similar study can be conducted in a large sample to generalize the findings.

$>$ A comparative study should be conducted in a different setting.

$>$ A similar study can be conducted in various age groups.

$>$ A true experimental study can be conducted with randomization.

$>$ A similar study can be conducted by using other non-pharmacological measures.

$>$ A Randomized controlled trial can be done on the same study in a large setting and with more samples.

\section{CONCLUSION}

The findings revealed that music playback was significantly effective in reducing pain among children during intravenous cannulation. Similar type of studies can be conducted in other settings.

\section{REFERENCE}

1. Greg Duncan, Ruth E.K. Stein, Mary Ellen O'Connell. Children's health, the nation's wealth: assessing and improving child health. NIH [Internet]. 2004 Available from https://www.ncbi.nlm.nih.gov/books/NBK92199.

2. Farion J.K, Splinter L.K, Newhook K. The effect of vapocoolant spray on pain due to intravenous cannulation in children: a randomized controlled trial. CMAJ.JAMC [Internet]. 2008 July [cited 2008 July]; 179(1): Available from https://www.google.com/search.

3. Singh S, Chanu S.E, Chaudhary A. Effectiveness of diversional activity on pain and anxiety during venipuncture among children in a selected hospital. PT [Internet]. 2017 Oct [cited 2017 Oct]; 7(4): Available from: https://www.omicsonline.org/open-access/effectiveness-of-diversional-activity-onpainand anxiety-during-venipuncture-among-children-in-a-selected-hospita I- dehradunuttar-2161-06651000334.pdf.

4. James J, Ghai S, Rao K.L.N, Sharma N. Effectiveness of Animated Cartoons as a distraction strategy on behavioural response to pain perception among children undergoing venipuncture. NMRJ [Internet]. 2011 Sep [cited 2012 Jul];8(3): Available from: http://medind.nic.in/nad/t12/i3/nadt123p19pdf

5. Kaur B, Sarin J, Kumar Y. Effectiveness of cartoon distraction on pain perception and distress in children during intravenous injection. IOSR-JNHS [Internet]. 2013 Jan [cited 2014 Jun]; 3(3). Available from:https://pdfs.semanticscholar.org/6170/85ac3323c1738ae9b6ab86a5a1d7bcca687c.pdf.

6. Simon V S, C P. Effectiveness of distraction techniques on pain relief during intravenous cannulation among the school children in a selected paediatric wards at Aims, Kochi. PJN [Internet]. 2014Jan[cited2014Jan];Availablefromhttps://www.researchgate.net/publication/321325690_Effectivenes s_ofdistractiontechniques_on_pain_relief_during_intravenous_cannulation_among_the_school_children_ in_selected_pediatric_wards_at_AIMS_Kochi_Pondicherry_Journal_of_Nursing_Vol_7_Issuep.

7. Young KD. Pediatric procedural pain. NCBI [Internet]. 2005 Feb [cited 2005Feb]; 54(2): Available from: https://www.ncbi.nlm.nih.gov/pubmed/15671974.

8. Shrestha R, Jeneta J. A study to evaluate the effectiveness of cartoon based diversional therapy on pain during intravenous medication among preschoolers in selected hospitals, Bangalore. IJHSR [Internet]. 2018 Nov [cited 2018 Nov]; 8(11): Available from: www.ijhrs.org. 